\title{
The Pathophysiology of Axonal Transport in Alzheimer's Disease
}

Elena Vicario-Orri ${ }^{\mathrm{a}, \mathrm{b}}$, Carlos Opazo $^{\mathrm{c}}$ and Francisco J. Muñoz ${ }^{\mathrm{a} *}$

${ }^{a}$ Laboratory of Molecular Physiology and Channelopathies, Departament de Ciències Experimentals i de la Salut (DCEXS), Universitat Pompeu Fabra (UPF), Barcelona, Spain

${ }^{\mathrm{b}}$ Department of Neurosciences, University of California, San Diego, La Jolla, CA, USA.

${ }^{\mathrm{c} O x i d a t i o n ~ B i o l o g y}$ Laboratory, The Florey Institute of Neuroscience and Mental Health, The University of Melbourne, Australia.

Running title: Axonal transport in Alzheimer's disease

* To whom correspondence should be addressed: Dr. Francisco J. Muñoz, Lab. Fisiologia Molecular i Canalopaties, Departament de Ciències Experimentals i de la Salut, Universitat Pompeu Fabra, C/ Dr. Aiguader 88, Barcelona 08003, Spain; Tel: +34 9331608 52; Fax: +34 9331609 01; e-mail: paco.munoz@upf.edu 


\begin{abstract}
Neurons communicate in the nervous system by carrying out information along the length of their axons to finally transmit it at the synapse. Proper function of axons and axon terminals relies on the transport of proteins, organelles, vesicles and other elements from the site of synthesis in the cell body. Conversely, neurotrophins secreted from axonal targets and other components at nerve terminals need to travel towards the cell body for clearance. Molecular motors, namely kinesins and dyneins, are responsible for the movement of these elements along cytoskeletal tracks. Given the challenging structure of neurons, axonal transport machinery plays a crucial role in maintaining neuronal viability and function, allowing the proper neurotransmitter release at the presynaptic ending. On this basis, failure of axonal transport has been proposed as a key player in the development and/or progression of neurodegenerative disorders such as Alzheimer's disease (AD). Increasing evidence suggests that amyloid- $\beta$ peptide, a hallmark of (AD), may disrupt axonal transport and in so doing, contribute to $\mathrm{AD}$ pathophysiology. Here we discuss the molecular mechanisms of axonal transport with specific emphasis on the possible relationship between defective axonal transport and AD.
\end{abstract}

Keywords: Axon; Alzheimer's disease; Amyloid- $\beta$ peptide; Fast axonal transport; Molecular motors;

\title{
INDEX
}

1. Introduction

2. Axonal transport

2.1 Anterograde transport

2.1.1 Kinesins 
2.1.2 Fast and slow axonal transport functions

2.2 Retrograde transport

2.2.1 Dyneins

2.2.2 Retrograde transport functions

3. Axonal transport defects in $\mathrm{AD}$

3.1 AD

3.1.1 Axonal transport impairment and AD: primary dysfunction

3.1.2 Secondary dysfunction of axonal transport in AD

3.1.2.1 A $\beta$ oligomers inhibit anterograde axonal transport

3.1.2.1.1 Downstream effects of $A \beta$ : kinases activity

3.1.2.1.2 Downstream effects of $A \beta$ : mitochondrial trafficking

3.1.2.1.3 Role of increased $\mathrm{A} \beta$ production in axonal transport

3.1.2.2 Role of tau in anterograde axonal transport

3.1.2.3 Defects in retrograde neurotrophins signaling

3.1.3 Synaptic dysfunction in $\mathrm{AD}$ as a consequence of FAT disruption

4. Conclusion 


\section{INTRODUCTION}

Alan Hodgkin and Andrew Huxley demonstrated in 1939, using the squid giant axon as an experimental model, that signal carried out along the axon is mediated by the active generation of an electrical potential, termed the action potential [1,2]. Later it was understood that action potentials trigger the release of neurotransmitters by depolarizing the axonal end, which allows the docking and subsequent fusion of the neurotransmitter vesicles. However, most of the proteins and cellular components that are essential for synaptic function are synthesized in the soma and transported long distances to reach the synaptic terminals. In this context, axonal transport is critical to maintain neuronal function and synaptic activity [35]. In this review, we aim to summarize the current knowledge on axonal transport and function as well as their pathological alterations in Alzheimer's disease (AD).

\section{AXONAL TRANSPORT}

The movement of cargoes inside cells is carried out by molecular motor proteins that move along cytoskeletal polymer tracks. Among the molecular motors that are involved in intracellular transport, three large superfamilies have been identified: kinesins, dyneins and myosins $[3,5]$. These motors differ in the tracks with which they engage, thus dynein and kinesin motors move along microtubules whereas myosins move along microfilaments $[6,7]$. Because of their length and organization, it is generally assumed that microtubules are the tracks for long-range axial movement in axons whereas microfilaments are the tracks for short-range movements [8]. In the present review we focus in those implicated in long-range movement as they might contribute higher to the maintenance of axon ending function.

Microtubules, the main component in the cytoskeleton, are tubular, dynamic and polarized structures composed of a long chain of $\alpha$ - and $\beta$-tubulin heterodimers undergoing continuous polymerization and depolymerization. The faster growing plus-end of 
microtubules point towards the axon terminal, while the slower growing minus-end point towards the soma. This polarity orientation, which is not seen in dendrites, has important implications for the directionality of axonal transport. Thus, kinesins move towards the plus ends and participate in anterograde transport, selectively transporting molecules from the cell body to axons. Retrograde transport is carried out mainly by cytoplasmic dyneins, which are minus-end motors that move molecules from the axonal terminals to the soma $[8,9]$.

Axonal transport is divided into fast and slow transport, differentiated by the movement rates and the cargoes involved. Slow anterograde transport is responsible for the movement of cytoskeletal elements and cytoplasm proteins at slow rates, and has been proposed to be involved in neuronal morphogenesis [10]. Fast axonal transport (FAT) is bidirectional: anterograde transport moves synaptic vesicles and organelles to the axon terminal whereas retrograde transport delivers trophic factors and returns old constituents to the cell body [8-10]. Since FAT is responsible for delivery of synaptic materials which ensures synaptic activity and neurotrophic factors that enhance neuronal survival; it is considered the key transport for neuronal survival and proper function.

While some cargoes have a fixed destination, others need to be distributed according to their own rules: mitochondria must be present along the axon but also concentrate in axon terminal and growth cones [14]. Consequently, many neuronal mitochondria are in motion, traveling in both anterograde and retrograde directions in order to be distributed along the full length of the axon [11-13].

Once a synapse is established, new components must continue to arrive to replace proteins and organelles targeted for degradation; the balance between the arrival and departure of components may determine whether a synapse is strengthened, weakened, or in a steady state [15]. Thus, axonal transport is more than just a monotonous transport down or back up the axon and is essential for the correct maintenance and survival of neurons. 


\subsection{Anterograde transport}

\subsubsection{Kinesins}

Biomolecules and components are transported anterogradely from the cell body to the axon terminal by members of the kinesin superfamily (KIFs; [16,17]), which comprises more than 40 proteins (Fig. 1). The general structural features of KIFs are defined by the structure of conventional kinesin, kinesin-I. Kinesin-I consists of two kinesin heavy chain (KHC) subunits and two kinesin light chains (KLC). The KHC comprises a globular motor domain, an $\alpha$-helical coiled-coil stalk domain and a carboxyl C-terminal tail domain. The globular motor domain shows a high degree of homology among kinesin family members and contains a microtubule-binding sequence and an ATP-binding sequence [5]. However, outside the motor domain, each KIF has a unique sequence. The range of diverse tail domains may confer unique cargo binding and regulatory specificity upon each kinesin protein $[4,5]$.

KIFs use the chemical energy of ATP to drive conformational changes that generate the motile force to transport cargoes along microtubules. Kinesins couple the binding, hydrolysis and release of ATP within their motor domains to a cycle of allosteric conformational changes that result in motion along the wall of the microtubule [8].

KIFs are classified into 14 kinesin families [18] that can be broadly grouped into three types, depending on the position of the motor domain in the molecule: N-kinesins have the motor domain in the amino-terminal region, M-kinesins have the motor domain in the middle and C-kinesins have the motor domain in the carboxy-terminal region. The position of the motor domain determines the directionality of the kinesin; accordingly, N-kinesins are directed towards the plus-end and C-kinesins towards the minus-end of microtubules. Most of the 14 families of kinesins are N-kinesins, the ones responsible for the anterograde transport [6].

\subsubsection{Fast and slow axonal transport functions}


FAT, which occurs at rates of approximately $200-400 \mathrm{~mm}$ /day [11,19], moves membrane bounded organelles (such as lysosomes or Golgi-derived vesicles), synaptic vesicle precursors (SVPs), active zone components in piccolo-bassoon transported vesicles (PTVs) $[6,12]$ ion channels [20,21], molecules that are abundant in growth cones [22], neurotransmitters, neuropeptides [12], membrane lipids and mitochondria [12,23,24] down the axon.

The diversity of the cargo-binding domains among kinesins explains how KIFs can transport numerous different cargoes [5]. However, cytoplasmic proteins and neurofilament proteins are transported by slow axonal transport [12].

Slow axonal transport comprises two kinetic components: slow component A which travels at a rate of $0.2-1 \mathrm{~mm} /$ day and carries neurofilament and microtubules protein such as tubulin, and slow component $\mathrm{B}$, which travels twice as fast as slow component A (2-8 $\mathrm{mm} /$ day) and moves proteins such as clathrin, actin, actin-binding proteins and cytosolic enzymes and proteins [11].

Recent evidences have shown that the so called "slow transport" is not really slow; indeed, its components are transported by fast motors perhaps similar or identical to the motors that move membranous organelles. But despite moving at fast rates, the average rate of movement is slow due to prolonged pauses between movements [8,25-27].

\subsection{Retrograde transport}

\subsubsection{Dyneins}

Dyneins are responsible for the minus end-directed retrograde transport that drives elements from the axon terminal to the cell body [28] (Fig. 2). Dyneins are a multi-subunit complex that consists of two catalytic dynein heavy chains (DHC) and several dynein light (DLC) and dynein intermediate chains (DIC) [9]. The DHC harbor the ATPase activity and 
bind microtubules, whereas the other chains are involved in cargo binding and binding to dynactin [29]. Indeed, dynein interacts with its cargoes via an adapter complex called dynactin, which consists of the protein $\mathrm{p} 150^{\text {glued }}$ (a subunit of the dynactin complex 1, DCTN1) and the p150 dynamitin (known as dynactin complex 2, DCTN2) along with many other subunits [9].

The composition of retrograde traffic, which moves at a rate of $150-300 \mathrm{~mm} /$ day, includes mitochondria, some synaptic vesicle components and endosomal recycling vesicles (containing neurotrophic factors) [11]. Viruses (herpes simplex, rabies and polio) [30] and toxins (tetanus toxin) [31] also appear to take advantage of retrograde transport to move from distal sites to neuronal cell bodies and infect the central nervous system (CNS).

Whereas the cargo specificity of kinesin is thought to depend on tail diversity, dynein cargo interactions are thought to be determined by the diversity of dynein-associated polypeptides [28]. However, C- type kinesins, from the kinesin-14 family, have the same directionality as dyneins and thus could potentially also serve as retrograde motors in axons [8].

\subsubsection{Retrograde transport functions}

Axonal retrograde signaling has conventionally been thought to rely on retrograde transport of endosomes containing endocytosed neurotrophin-receptor complexes to neuronal cell bodies [32-34]. These endosomes are then responsible for evoking the changes in gene expression and metabolic activity required for survival and differentiation. This hypothesis, known as the "signaling endosome hypothesis" was first proposed by Mobley and colleagues [35] and has been further supported by mounting evidence indicating that both tyrosine receptor kinase (Trk) and their neurotrophin ligands undergo endocytosis and retrograde transport [36-39]. 
On the other hand, the retrograde axonal transport of proteins also allows the neurons to receive information about the external environment surrounding the nerve terminal. In many regions of the nervous system, signals produced by target cells and surrounding glia or in response to injury are received at axon terminals and then retrogradely propagated to the cell body where they regulate gene transcription and other cellular processes required for development and adult function [34]. This information allows neurons to respond to a number of extracellular signals in different ways, for instance, by either surviving or undergoing apoptosis, destabilizing or strengthening synaptic connections with targets, or inducing changes in neuronal phenotype. Other functions of retrograde axonal transport may include the removal of unwanted proteins from the nerve terminal region, and the retrieval of material which would otherwise be removed from the neuron [32].

\section{AXONAL TRANSPORT DEFECTS IN AD}

Axonal transport is essential for the proper function of neurons and thus, the dysfunction of any of the components involved, from the molecular motors themselves to a lack of energy for the ATP-dependent motors or alterations in the connection between motors and their cargos, has been implicated in various neurologic diseases. The identification of primary mutations in the axonal transport machinery has provided convincing evidence for the alteration of FAT as the cause for the pathology in several diseases including hereditary spastic paraplegia (HSP), Charcot-Marie-Tooth disease (CMT), spinal and bulbar muscular atrophy (SBMA; also known as Kennedy's disease) and Perry syndrome.

HSP comprises a heterogeneous inherited group of lower motor neuron diseases, characterized by progressive limb spasticity and weakness. Several forms of HSP are caused by mutations in genes related to intracellular trafficking. In particular, a missense mutation in the KIF5A gene, encoding for a anterograde-specific molecular motor, kinesin 5, was found 
in a family with HSP type 10 [40]. Moreover, the pathogenic mutants of KIF5A produced dysfunction of anterograde transport in vitro [41]. Mutations in another kinesin, KIF1B, were identified as responsible for CMT disease type 2A, a common inherited peripheral neuropathy, characterized by motor and sensory deficits. Also, knock-out mice models of KIF1B developed progressive muscle weakness and symptoms similar to CMT type 2 [42]. One of the proteins involved in retrograde transport is mutated in SBMA, a lower motor neuron disease caused by a polyQ expansion in the androgen receptor (AR). The mutation was found in the p150 subunit of DCTN1 which is essential for the binding of dynein to cargo [43]. Other DCTN1 mutants cause a neurodegenerative disorder with parkinsonism and dementia, known as Perry syndrome [44] (Table 1).

In all the aforementioned neurodegenerative disorders, there are also other mutations and proteins that cause secondary dysfunction of FAT. For instance, the most common mutations involved in about $40 \%$ of the autosomal dominant forms of HSP are in the gene SPG4, which encodes spastin, an ATPase that regulates microtubule dynamics [45]. Knockout mice for this gene show accumulation of organelles and cytoskeleton protein and progressive swelling of the axon, indicating an impairment in axonal transport [46]. Moreover, mutant spastin is able to disrupt FAT in the squid axoplasm [47]. Similary, mutations in MFN2 and RAB7, which code for mitofusin-2 and Rab-7 protein respectively, have been identified in cases of CMT type 2. Mitofusin-2 is a mitochondrial GTPase involved in the transport of mitochondria along the axon. MFN2 mutants disrupt both anterograde and retrograde mitochondrial transport $[48,49]$. Rab-7 regulates endosomal and lysosomal retrograde transport [50,51]. Another example is SBMA, in which the polyQ AR expression causes the phosphorylation of KHCs by c-Jun NH2-terminal kinase (JNK) and prevents kinesin-I binding to microtubules [52]. 
When looking at the latter cases, the mechanisms by which FAT defects cause the development or progression of the disease are not well understood and the causative role of FAT is as yet inconclusive. However, in these pathologies, the presence of primary mutations in axonal transport elements has provided direct evidence that FAT defects are a key player in the development of the diseases. This has allowed for the extrapolation of this hypothesis to other neurodegenerative disorders in which primary mutations associated with axonal transport machinery have not been described and the role for FAT defects is not as clear. This is the case for such common neurodegenerative diseases as Huntington's disease, Parkinson's disease, amyotrophic lateral sclerosis (ALS) or $\mathrm{AD}$, in which the known proteins causing the disorder, huntingtin [53,54], $\alpha$-synuclein [55], superoxide dismutase 1 (SOD1) [56] and A $\beta$ [57] or tau [58] respectively, have been shown to affect in one way or another the axonal transport machinery [59,60]. For example, polyglutamine huntingtin causes tubulin deacetylation which in turn prevents the binding of the motor proteins to the microtubules $[53,54]$, and SOD1 activates p38 and the subsequent phosphorylation of KLC inhibits its binding to the cargo [56] (Table 2).

We are particularly interested in elucidating the role of FAT dysfunction in the pathogenesis of $\mathrm{AD}$. Thus this review will try to compile all the evidence so far in relation to this issue.

\subsection{AD}

$\mathrm{AD}$ is a neurodegenerative process that affects firstly the hippocampus and temporal cortex and then the whole brain as the disease progresses. It is characterized by the presence of two histopathological hallmarks: senile plaques and neurofibrillary tangles (NFT). Senile plaques are formed by insoluble aggregates of amyloid- $\beta$ peptide $(\mathrm{A} \beta)[61,62]$, a peptide released by the cleavage of the amyloid precursor protein $(\mathrm{A} \beta \mathrm{PP})$ through the sequential 
action of the $\beta$-secretase protein (beta-site A $\beta$ PP cleaving enzyme 1; BACE1) and $\gamma$-secretase, a multi-protein complex in which presenilins (PS) are the catalytic subunits [63-65]. These aggregates are surrounded by dystrophic neurites bearing NFT, which consists of intracellular aggregates of the tau microtubule-associated protein in a hyperphosphorylated state [66].

Several lines of evidence suggest that disruption of axonal transport is a hallmark of many neurodegenerative diseases such as $\mathrm{AD}$. $\mathrm{A} \beta \mathrm{PP}, \mathrm{BACE} 1$ and $\mathrm{PS} 1$, the major proteins involved in $\mathrm{AD}$ etiology and progression, undergo axonal transport, therefore they might be affected. Futhermore $A \beta$ and tau seem to play an essential role in transport along the axons. Other data demonstrates that $\mathrm{AD}$ is also associated with unbalanced distribution and dysregulation of neurotrophins due to impaired axonal transport.

\subsubsection{Axonal transport impairment and AD: primary dysfunction}

Unlike other neurodegenerative diseases, there is no known specific mutation in the molecular machinery of axonal transport that results in AD. However, some evidence suggests that axonal transport defects might be the primary mechanism underlying the disease. Axonal transport defects may represent an early stage in AD pathogenesis as axonal swelling and reduced transport are observed before other AD hallmarks appear in human brains and in transgenic mouse models of $\mathrm{AD}$ [67]. Indeed, transgenic mice overexpressing AD-related proteins such as wild-type or mutant A $\beta P P[54,55]$ or mutant PS1 $[67,68]$ display axonal transport dysfunction. Familial AD (FAD) mutations in PS1 might contribute to neuronal degeneration by altering kinesin-based transport mechanisms and impairing FAT of axonal cargoes $[69,70]$. These axonal transport impairments are also observed in transgenic mice expressing human ApoE4, a gene associated with increased risk of AD [71]. Furthermore, a polymorphism in the KLC1 subunit of kinesin-1 was found to be significantly 
associated with $\mathrm{AD}$, though a larger scale study should be carried out to further confirm this [72].

On the other hand, since AD-related proteins, such as A Disintegrin And Metalloproteinase domain-containing protein 10 (ADAM10), A $\beta P P$, BACE1, PS1 and Tau, are transported down the axon by axonal transport machinery, failure of these proteins to reach their destination or their accumulation due to impaired transport could also lead to the development of the disease.

A $\beta$ PP undergoes fast anterograde axonal transport [73] by an indirect interaction via JNK interacting protein 1 (JIP1) [74-76]. JIP1 binds to a conserved 11-aa motif located at the C-terminus of KLC [77]. Additionally, recent evidence shows that the scaffolding protein JIP1 is also responsible for coordinating A $\beta$ PP bidirectional transport by switching between anterograde and retrograde motile complexes as knocking out its expression in neurons produces deficits in the anterograde and retrograde transport of A $\beta$ PP. JIP 1 interacts with both KLC and p150 and its phosphorylation by JNK determines the directionality of A $\beta P P$ transport [78]. Also, A $\beta$ PP functions as a kinesin-I membrane receptor, mediating the axonal transport of BACE1 and PS1 [79]. In fact, A $\beta P P, B A C E 1$ and PS1 are thought to travel anterogradely within the same vesicle-like membrane compartment and processing of A $\beta P P$ to amyloid- $\beta$ by secretases can occur in this compartment transported by kinesin-I $[79,80]$, though there is some controversy regarding this model $[81,82]$. A recent study showed actually that it is upon neuronal activity induction that BACE1 and $\mathrm{A} \beta \mathrm{PP}$ vesicles merge and thus facilitate A $\beta P P$ cleavage [83].

Tau protein also undergoes axonal transport, though it is thought to be much slower. In fact, the rate of anterograde transport of tau was in accordance with the reported rate for the slow component of axonal transport $[84,85]$. Nonetheless, other studies have shown that tau 
move at rates consistent with fast transport, albeit infrequently [86]. This agrees with recent findings reporting that cytoskeletal proteins such as neurofilaments, vimentin or tubulin, which were previously thought to move in the slow component of axonal transport, are probably rapidly transported by fast motors including kinesin and dynein molecular motors [87-90]. The rapid movement coupled with frequent pauses combine for an overall slow rate of transport $[8,26,27]$.

\subsubsection{Secondary dysfunction of axonal transport in AD}

\subsubsection{A $\beta$ oligomers inhibit anterograde axonal transport}

Both monomeric and fibrillar $A \beta[91,92]$ have been shown to disrupt axonal transport. However, since mounting evidence suggested soluble oligomers of $A \beta$ (A $\beta \mathrm{Os}$ ) to be the most neurotoxic species responsible for synapse failure and early $\mathrm{AD}$ pathogenesis, the role of A $\beta O$ s in the disruption of FAT was assessed. A $\beta O$ s inhibited FAT when applied to squid [57] or to murine hippocampal neurons [93]. Though evidence shows that $A \beta$ might disrupt both anterograde and retrograde transports. However, most reports have shown that $\mathrm{A} \beta$ has a greater effect on the anterograde transport [92,94-96]. In this regard, it is plausible that a defect in anterograde-moving mitochondria or synaptic vesicles could lead to dysfunction of synaptic activity and neuronal degeneration, features of $\mathrm{AD}$ pathology. While it is clear that $\mathrm{A} \beta$ impairs FAT, the mechanisms by which $\mathrm{A} \beta$ affects transport remain elusive. Some studies suggested that $\mathrm{A} \beta$ exerts its inhibitory effects via actin polymerization and aggregation [91], but it has been further demonstrated that $\mathrm{A} \beta$ did not cause major alterations to the cytoskeleton nor to the microtubule network which remained intact [92,93]. Thus, a dysregulation of intracellular signaling cascades, instead of disintegration of cytoskeleton, might be the cause behind FAT disruption in AD. 
It is important to consider that most reports have used micromolar concentrations of $\mathrm{A} \beta$ to show dramatic reductions of axonal transport. Thus, the use of high levels of $A \beta$ could lead to non-specific toxicity that secondarily impairs axonal transport. However, it has been also possible to observe changes in axonal transport induced by low concentration of $A \beta$ [91]. Tang et al. used small quantities of $\mathrm{A} \beta$ and still showed a small decrease in the velocity of some cargoes, suggesting that effects on axonal transport are not dependent on generic A $\beta$ related toxicity. Also, and unlike previous reports [91], they demonstrated that transport defects induced by $\mathrm{A} \beta$ are reversible upon washout of the oligomers [97].

\subsection{Downstream effects of Aß: kinases activity}

Many pieces of evidence indicate that FAT disruption by $\mathrm{A} \beta$ is dependent on both $\mathrm{N}$ methyl D-aspartate receptor (NMDAR) and glycogen synthase kinase-3 $\beta$ (GSK3 $\beta$ ) since NMDAR antagonists and inhibition of GSK3 $\beta$ prevented A $\beta$-mediated FAT disruption [92,93,97] (Fig. 3). Both NMDAR and GSK3 $\beta$ are functionally related since during long-term potentiation (LTP) the activation of NMDA and PI3K/Akt phosphorylates and inactivates GSK3 $\beta$, thus preventing the induction of long-term depression (LTD). In turn, activation of the phosphatase PP1 during LTD causes dephosphorylation and subsequent activation of GSK3 $\beta$ and inhibition of Akt [98]. A $\beta$ Os have been shown to affect NMDAR function, inducing abnormal calcium influx, neuronal oxidative stress [99] and aberrant activation of kinases, including GSK3 $\beta$ [100-102]. Although both drugs are thought to affect multiple pathways in $\mathrm{AD}$, it is worth noting here that the NMDAR antagonist memantine is one of the few treatments approved for $\mathrm{AD}[103,104]$ and GSK3 $\beta$ inhibitors are being studied as a possible therapeutic agent too [105-107].

A $\beta$ Os appear to interfere with NMDAR and cause LTD-like stimuli, activating GSK3 $\beta$ and thus disrupting axonal transport $[93,98,108]$. PS1 mutations also impair axonal transport 
by increasing GSK3 $\beta$ activity $[69,70]$. Presumably, according to the model that has been proposed, GSK3 $\beta$ inhibits kinesin-I by phosphorylating KLC and causing cargo to dissociate from the motor complex [109]. Most studies are in agreement with this model and suggest that GSK3 $\beta$ acts as a negative regulator of kinesin-I. For instance, an excess of GSK3 $\beta$ reduces anterograde mitochondrial movement in neural cells [110], whereas inhibiting GSK3 $\beta$ enhances anterograde mitochondrial transport in hippocampal neurons [111]. Furthermore, reducing GSK3 $\beta$ levels enhances anterograde and retrograde transport of A $\beta P P$ in Drosophila melanogaster [112].

Impairment of long-term potentiation by $\mathrm{A} \beta \mathrm{O}$ s is also prevented by inhibitors of casein kinase-2 (CK2), suggesting a possible role of CK2 in axonal transport [57]. In fact, A $3 \mathrm{Os}$ were able to stimulate CK2 kinase activity in vitro [113]. It has been demonstrated that the mode of FAT inhibition of both GSK3 $\beta$ and CK2 is similar, involving the phosphorylation of KLC which promotes detachment of conventional kinesin from its transported cargoes, leading to a reduction of FAT $[57,58,109]$. However, unlike GSK3 $\beta$, which only affects anterograde FAT, overexpression of $\mathrm{CK} 2$ and $\mathrm{A} \beta \mathrm{O}$ s inhibit both directions, suggesting that CK2 can affect dynein as well [57]. Another study demonstrated that the inhibition of FAT by polyQ-AR was dependent on the activation of JNK. Active JNK was able to phosphorylate KHC and inhibited kinesin-1 microtubule binding activity [114]. However, the mechanism of A $\beta O$ s-mediated activation of $\mathrm{JNK}$ or whether $\mathrm{A} \beta \mathrm{Os}$ can even directly activate the JNK pathway is unknown.

The alterations in the signaling pathways presented above fit with the fact that alterations or dysregulation in the activity of protein kinases and abnormal phosphorylation are key features of AD [109,115,116]. Indeed, GSK3 $\beta$ can be activated by fibrillar forms of $\mathrm{A} \beta$ [117] and active GSK3$\beta$ is found in association with NFT in AD brains and is the main kinase thought to be involved in the hyperphosphorylation of tau [114]. Also, the kinase 
activities of CK2 and JNK are elevated in AD [115,116]. Therefore, CK2, GSK3 $\beta$ and JNK might contribute to the axonal transport failure observed in $\mathrm{AD}$ by phosphorylating kinesin and thus promoting a premature uploading of the cargoes at an incorrect segment of the axon.

\subsection{Downstream effects of Aß: mitochondrial trafficking}

There is also controversy regarding the effect of $A \beta$ on mitochondrial trafficking. Most studies indicate that $\mathrm{A} \beta$ severely disrupt mitochondrial transport $[92,93,95,96]$, whereas others showed no effects on mitochondrial motility [97]. However, A $\beta$ has been reported to impair mitochondrial morphology [119] and function, including the disruption of membrane properties, calcium homeostasis, oxidative phosphorylation and ROS production among others [120]. In particular, ROS produced in the mitochondria are thought to activate GSK3 $\beta$ since the activity of this enzyme is inhibited by antioxidant treatment with melatonin [121]. Accordingly, reducing the production of mitochondrial superoxide by overexpression of superoxide dismutase 2 (SOD2) rescued the axonal transport deficits typically shown in Tg2576 mice [122]. On this basis, A $\beta$-induced mitochondrial dysfunction has been suggested to decrease axonal transport in neurons [123]. This is in accordance with the finding that the deficiency of mitochondrial ATPase paraplegin disrupts both anterograde and retrograde transport in a mouse model of HSP [124].

\subsection{Role of increased $A \beta$ production in axonal transport}

There are some studies suggesting a causal relationship between failed axonal transport and $A \beta$ generation and its aberrant accumulation. For instance, some studies have shown that $\mathrm{A} \beta \mathrm{PP}$ processing might occur during its axonal transport and that the production of $A \beta$ is stimulated by inhibition of axonal transport [79]. Accordingly, it is been shown that reduction of kinesin-1 promotes axonal defects, increases $\mathrm{A} \beta$ generation and enhances amyloid deposition in Drosophila and mice [67,125]. However, this view has been refuted by 
some researchers who showed that $\mathrm{A} \beta \mathrm{PP}$ and $\mathrm{BACE} 1$ move in different vesicles and so $\mathrm{A} \beta \mathrm{PP}$ cleavage might not occur within moving vesicles [126]. Another recent study showed that $\mathrm{A} \beta \mathrm{PP}$ and $\mathrm{BACE} 1$ vesicles merged upon neuronal stimulation suggesting that overproduction of $A \beta$ may be dependent on increased neuronal activity, although this does not preclude an additional contribution by axonal transport deficits [83].

On the other hand, $\mathrm{A} \beta$ per se might directly induce impairments in axonal transport $[91-95,97]$. Whether aberrant $A \beta$ production is the primary cause underlying axonal transport deficits or whether this aberrant $A \beta$ generation is the result of impaired axonal transport is unclear. Moreover, subtle changes in axonal transport functionality due to old age could enhance $A \beta$ generation and this in turn would induce further deterioration of axonal transport $[67,127]$. However, the etiological cause of this vicious cycle is as yet unclear.

\subsubsection{Role of tau in anterograde axonal transport}

Tau is a microtubule-associated protein involved in microtubule dynamics and maintenance [128]. Since axonal transport is highly dependent on microtubule tracks and tau aggregates play a key role in AD pathology, the effects of tau on microtubule-dependent FAT have been explored. Unlike with $A \beta$, the effect of tau on axonal transport is still inconclusive. Several studies have reported that tau perfusion in the squid axoplasm [58] or tau overexpression in cortical neurons, retinal ganglion cells, neuroblastoma cells and CHO cells $[129,130]$ inhibited axonal transport. The observed impairment preferentially affected anterograde kinesin-dependent transport, whereas dynein-mediated movements were less affected [58,129-131]. As a result, mitochondria and other vesicles accumulated within the cell body and disappeared from the neurites [130]. Similarly, transgenic mice overexpressing the shortest human tau isoform in CNS neurons showed filamentous tau inclusions and 
insoluble hyperphosphorylated tau, typical features of $\mathrm{AD}$, as well as impaired FAT. Interestingly, treatment with microtubule-stabilizing drugs restored FAT [132].

A mechanism proposed for tau regulation of kinesin-based transport proposes a competition between tau and kinesin-1 for the kinesin-1 binding site on microtubules $[129,130]$. Indeed, tau constructs lacking the microtubule-binding repeats (MTBRs) did not show this effect [130]. In addition, tau could regulate fast axonal transport by alternative mechanisms. For example, tau filaments directly activate the phosphatase PP1, causing the dephosphorylation and activation of axonal GSK3$\beta$. Activated GSK3 3 phosphorylates KLCs, prompting dissociation of kinesin-1 and cargo [58,109]. Accordingly, GSK3 $\beta$ has been reported to phosphorylate tau and subsequently increase its binding to kinesin-1 [133]. So, it is also possible that when tau is overexpressed it could sequester kinesin, preventing the molecular motor from binding to other cargoes and thus allowing the accumulation of neuronal components in the cell body. Indeed tau overexpression impairs mitochondrial transport but does not inhibit its own transport along axons $[85,129]$.

On the other hand, Yuan et al. reported that the overexpression of the wild-type form of tau did not affect rates of transport along axons in vivo [134], suggesting that only overexpression at high levels or mutations that affect its phosphorylation state may play a role in axonal transport. This is consistent with another study in which high levels of monomeric tau did not affect either in vitro axonal transport or in squid axoplasm [114]. Whether tau affects axonal transport is as yet controversial, but recent studies showed that it somehow might play a role. Indeed, tau reduction has been reported to prevent $A \beta$-induced defects in axonal transport in transgenic mice $[135,136]$ suggesting a connection between tau and $A \beta$ effects.

\subsubsection{Defects in retrograde neurotrophins signaling}


Neurotrophins are a family of homodimeric and secreted proteins that include nerve growth factor (NGF), brain-derived neurotrophic factor (BDNF), neurotrophin 3 (NT3) and neurotrophin 4/5 (NT4/5). Neurotrophins bind to two types of receptors - a high affinity Trk and a low-affinity pan-neurotrophin receptor (p75). Each Trk is preferentially activated by one or more NTs - TrkA by NGF, TrkB by BDNF and NT-4/5, and TrkC by NT-3 — and is responsible for mediating a wide range of cellular responses including within neurons cell survival, proliferation, fate of neural precursors, axon and dendrite growth and patterning. Trk receptors also regulate synaptic strength and plasticity [137-139]. Neurodegenerative diseases such as $\mathrm{AD}$ are linked to imbalanced distribution and dysregulation of neurotrophins $[138,140,141]$. Moreover BDNF has been demonstrated to protect neurons against $\mathrm{A} \beta$ neurotoxicity [142].

BDNF is considered a major regulator of synaptic plasticity and plays an essential role in learning and memory, neuronal survival and development [143] and has neuroprotective effects in rodent and primate models of AD [144]. It has been shown that mRNA and protein levels of BDNF are reduced in the hippocampus and neocortex of AD brains as well as the levels of its full-length receptor TrkB [141,145-147]. Moreover, polymorphisms in the BDNF gene have been associated with higher risk of $\mathrm{AD}$, though there is still some controversy [148-152]. BDNF-TrkB signaling is based on axonal transport. BDNF activates TrkB in axon terminals and the formation of the ligand-receptor complex initiates their internalization into endosomes, which requires $\mathrm{Ca}^{2+}$ influx [153], and their retrograde transport along microtubules $[123,154]$. The movement of the BDNF-TrkB signaling endosome depends on TrkB activation since a kinase-dead receptor variant is neither phosphorylated in response to BDNF nor transported retrogradely. Also this retrograde transport depends on clathrinmediated endocytosis, since its inhibition prevents internalization and retrograde transport of TrkB after BDNF treatment. Finally, disruption of dynein function reduces Trk trafficking 
and thus abolishes the ability of BDNF to support survival of neurons, suggesting this transport is also dynein-dependent [155]. Impairment of anterograde transport is thought to be caused by $\mathrm{A} \beta$-induced activation of GSK3$\beta$ which causes phosphorylation of kinesin and subsequent release of the cargoes [109]. Unlike with anterograde transport, it is not known the mechanism by which $A \beta$ interacts with dynein.

However, what is most interesting is the reported ability of $A \beta$ to impair this BDNF retrograde trafficking. In fact, it has been found that the retrograde transport rate of BDNFGFP vesicles and the somatic accumulation of BDNF-GFP are significantly reduced in AD transgenic mouse neurons [156]. This finding is in agreement with a study in which A $\beta P P$ overexpression disrupted NGF retrograde transport with a concomitant cholinergic neurodegeneration [68]. However, Cotman and colleagues also found that the retrograde transport deficit was reversed using $\gamma$-secretase inhibitors, suggesting that increased $A \beta$ levels and not total $\mathrm{A} \beta \mathrm{PP}$ was responsible for these transport deficits. Also $\mathrm{A} \beta \mathrm{O}$ s alone were capable of impairing BDNF trafficking in wild-type neurons [156]. The differences between these results can be attributed to the use of different neurotrophins (BDNF vs. NGF), different neuronal types (cortical vs. basal forebrain cholinergic neurons) and/or different models (tg2576 neurons vs. Ts65Dn mice). In fact, Ts65Dn is a Down syndrome (DS) mouse model that carries an extra chromosome with triplicated copies of many other genes in addition to A $\beta P P[157]$

On the other hand, mitochondria are important for axonal transport of neurotrophic factors [158]. Since A $\beta$ is known to impair mitochondrial function and trafficking, BDNFTrkB signaling could be affected by a lack of energy supply for the retrograde axonal transport [123]. Another interesting link between neurotrophins and AD is the fact that the progression of tau pathology in $\mathrm{AD}$ is follows the neuroanatomical track of the BDNF 
retrograde transport pathway. In the adult brain, BDNF is mainly produced in the entorhinal cortex and traffics to the subiculum and CA1 fields and then to the basal forebrain and amygdale, which is the neuroanatomical track for the progression of neurofibrillary tangles in $\mathrm{AD}[159]$.

\subsubsection{Synaptic dysfunction in AD as a consequence of FAT disruption}

Synaptic loss, which occurs early in AD development, is considered the best pathological correlate of cognitive deficits $[160,161]$. While it is clear that $A \beta$ can directly disrupt synapses, there are other indirect mechanisms through which $\mathrm{A} \beta$ could cause synapse degeneration. It is likely that synaptic dysfunction in $\mathrm{AD}$ may be caused by axonal transport defects. Indeed, axonal transport is essential to transport many synaptic elements needed for the proper functioning of the synapse. For instance, synapses are sites of high-energy demand and in need of a great number of mitochondria. Electron microscopy and immunohistochemistry showed mitochondria located near the presynaptic membrane and tethered to vesicle release sites [162]. Synaptic transmission requires mitochondrial ATP generation and control of $\mathrm{Ca}^{2+}$ for neurotransmitter exocytosis, vesicle recruitment and synaptic plasticity, among others. Mitochondria have been demonstrated to act as the main $\mathrm{Ca}^{2+}$ buffers at synapses, uptaking and releasing $\mathrm{Ca}^{2+}$ to regulate the cytosolic concentrations needed for normal neurotransmission [24,163-166]. Therefore, the impairment of mitochondrial supply to the synapses could lead to synaptic dysfunction and degeneration.

In line with this hypothesis, mutations of Dynamin-related protein 1 (Drp-1) in Drosophila that affect mitochondrial transport and distribution also resulted in defective synaptic transmission. These studies demonstrated synaptic depression and asynchronous release of neurotransmitters but only showed modest effects on $\mathrm{Ca}^{2+}$ levels, suggesting that calcium buffering in the absence of mitochondria is not the main cause of the physiological 
defects in these mutants [166-169]. Thus, the other major defect in synapses lacking mitochondria might be related to ATP production. In accordance with this, Verstreken et al. found that giving ATP to neurons could partially rescue synaptic depression of drp1 mutants [170]. Moreover, Calkins et al. reported decreased mitochondrial numbers and motility in A $\beta$ treated mouse hippocampal neurons and suggested this impairment in axonal transport as a likely cause for the decrease in synaptophysin staining [95].

Besides mitochondria, SVPs and PTVs are crucial to the nerve terminal and its proper function. PTVs are the core components of the presynaptic cytomatrix at the active zone of neurotransmitter release, tethering proteins that mediate efficient synaptic vesicle clustering. Both PTVs and SVPs are transported anterogradely along axons and their arrival at and departure from an established synapse may determine whether this synapse is strengthened or weakened $[171,172]$. So, impaired axonal transport and the inability of those components to reach the synapse could lead to inappropriate synaptic function and ultimately, its degeneration [57,70]. Additionally, as discussed earlier, appropriate neurotrophic support depends on axonal transport and its disruption may cause defective neurotrophic function and ultimately lead to neurodegeneration [70].

In support of this hypothesis relating synapse degeneration and axonal transport, mutations in conventional kinesin and dynein that impair anterograde and retrograde transport respectively, showed degeneration of sensory and motor neurons [40,173,174]. Altogether, all the aforementioned data indicate that deficits in FAT could be underlying synapse loss seen in various neurodegenerative diseases.

\section{CONCLUSION}

Axonal transport is of the utmost importance for the proper maintenance and function of neurons. Its disruption has been proposed as a hallmark of several neurodegenerative 
diseases. In particular, many pieces of experimental evidence are consistent with the fact that axonal transport defects could be the cause behind AD pathology. Key proteins to $\mathrm{AD}$ pathology such as $A \beta$ and tau have been shown to disrupt transport machinery and thus deprive axonal terminals of the necessary elements for their function. This could subsequently lead to synaptic dysfunction and degeneration, both shown in AD. However, the precise role of such axonal transport defects in the onset of the disease remains to be elucidated. Also, whether the defective axonal transport is the primary cause leading to the disease or if it is just a consequence of $\mathrm{AD}$ pathology is still inconclusive. These questions will be the subject of future studies in the field.

\section{ACKNOWLEDGMENTS}

We would like to acknowledge Dr. Edward H. Koo and Karen Chiang for their suggestions and extensive revision of this manuscript. Supported by the Plan Estatal de I+D+i 2013-2016 and the ISCIII-Subdirección General de Evaluación y Fomento de la Investigación (Grants PI13/00408, and Red HERACLES RD12/0042/0014) and FEDER Funds; Generalitat de Catalunya (SGR09-1369); and Fundació la Marató de TV3 (100310). E.V is supported by a fellowship from Fundació La Caixa. Figures were produced using Servier Medical Art. All the authors do not have any conflict of interest regarding the present work.

\section{REFERENCES}

[1] Hodgkin A, Huxley A (1939) action potentials recorded from inside a nerve fibre. Nature 144, 710-711.

[2] Hodgkin A, Huxley A (1952) The components of membrane conductance in the giant axon of loligo. J. Physiol. 116, 473-496.

[3] Vale RD (2000) The Way Things Move: Looking Under the Hood of Molecular Motor Proteins. Science (80-. ). 288, 88-95.

[4] Goldstein LS (2001) Kinesin molecular motors: transport pathways, receptors, and human disease. Proc. Natl. Acad. Sci. U. S. A. 98, 6999-7003.

[5] Hirokawa N, Takemura R (2005) Molecular motors and mechanisms of directional transport in neurons. Nat. Rev. Neurosci. 6, 201-14. 
[6] Hirokawa N, Noda Y (2008) Intracellular Transport and Kinesin Superfamily Proteins, KIFs: Structure, Function, and Dynamics. Physiol. Rev. 88, 1089-1118.

[7] Hirokawa N, Noda Y, Tanaka Y, Niwa S (2009) Kinesin superfamily motor proteins and intracellular transport. Nat. Rev. Mol. Cell Biol. 10, 682-96.

[8] Brown A (2003) Axonal transport of membranous and nonmembranous cargoes: a unified perspective. $J$. Cell Biol. 160, 817-21.

[9] Hirokawa N (1998) Kinesin and Dynein Superfamily Proteins and the Mechanism of Organelle Transport. Science (80-. ). 279, 519-526.

[10] Baas PW, Buster DW (2004) Slow axonal transport and the genesis of neuronal morphology. $J$. Neurobiol. 58, 3-17.

[11] Lasek RJ, Garner J a, Brady ST (1984) Axonal transport of the cytoplasmic matrix. J. Cell Biol. 99, 212s-221s.

[12] Brady ST (1991) Molecular motors in the nervous system. Neuron 7, 521-33.

[13] Vallee R, Bloom G (1991) Mechanisms of fast and slow axonal transport. Annu. Rev. Neurosci. 14, 5992.

[14] Laughlin SB, de Ruyter van Steveninck RR, Anderson JC (1998) The metabolic cost of neural information. Nat. Neurosci. 1, 36-41.

[15] Dobrunz LE, Garner CC (2002) Priming plasticity. Nature 415, 277-8.

[16] Vale RD, Reese TS, Sheetz MP (1985) Identification of a novel force-generating protein, kinesin, involved in microtubule-based motility. Cell 42, 39-50.

[17] Brady S (1985) a novel brain ATPase with properties expected for the fast axonal transport.

[18] Lawrence CJ, Dawe RK, Christie KR, Cleveland DW, Dawson SC, Endow S a, Goldstein LSB, Goodson H V, Hirokawa N, Howard J, Malmberg RL, McIntosh JR, Miki H, Mitchison TJ, Okada Y, Reddy ASN, Saxton WM, Schliwa M, Scholey JM, Vale RD, Walczak CE, Wordeman L (2004) A standardized kinesin nomenclature. J. Cell Biol. 167, 19-22.

[19] Grafstein B, Forman DS (1980) Intracellular transport in neurons. Physiol. Rev. 60, 1167-283.

[20] Garrido J, Fernandes F (2001) Identification of an axonal determinant in the C-terminus of the sodium channel Nav1.2. EMBO J. 20, 5950-5961.

[21] Gu C, Jan YN, Jan LY (2003) A conserved domain in axonal targeting of Kv1 (Shaker) voltage-gated potassium channels. Science 301, 646-9.

[22] Vogt L, Giger R, Ziegler U, Kunz B (1996) Continuous renewal of the axonal pathway sensor apparatus by insertion of new sensor molecules into the growth cone membrane. Curr. Biol. 6, 1153-1158.

[23] Tanaka Y, Kanai Y, Okada Y, Nonaka S (1998) Targeted disruption of mouse conventional kinesin heavy chain, kif5b, results in abnormal perinuclear clustering of mitochondria. Cell 93, 1147-1158.

[24] Hollenbeck P (2005) Mitochondria and neurotransmission: evacuating the synapse. Neuron 47, $331-333$.

[25] Shah J, Cleveland D (2002) Slow axonal transport: fast motors in the slow lane. Curr. Opin. Cell Biol. 14, 58-62.

[26] Roy S, Coffee P, Smith G, Liem RK, Brady ST, Black MM (2000) Neurofilaments are transported rapidly but intermittently in axons: implications for slow axonal transport. J. Neurosci. 20, 6849-61.

[27] Wang L, Ho CL, Sun D, Liem RK, Brown a (2000) Rapid movement of axonal neurofilaments interrupted by prolonged pauses. Nat. Cell Biol. 2, 137-41.

[28] King S (2000) The dynein microtubule motor. Biochim. Biophys. Acta 1496, 60-75.

[29] Stokin GB, Goldstein LSB (2006) Axonal transport and Alzheimer's disease. Annu. Rev. Biochem. 75 , 607-27.

[30] Bearer E (2000) Retrograde axonal transport of herpes simplex virus: evidence for a single mechanism and a role for tegument. Proc. Natl. Acad. Sci. U. S. A. 97, 8146-8150.

[31] Lalli G, Gschmeissner S, Schiavo G (2003) Myosin Va and microtubule-based motors are required for fast axonal retrograde transport of tetanus toxin in motor neurons. J. Cell Sci. 116, 4639-50.

[32] Reynolds A, Bartlett S, Hendry I (2000) Molecular mechanisms regulating the retrograde axonal transport of neurotrophins. Brain Res. Rev. 33, 169-178.

[33] Ibáñez C (2007) Message in a bottle: long-range retrograde signaling in the nervous system. Trends Cell Biol. 17, 519-528.

[34] Ginty D, Segal R (2002) Retrograde neurotrophin signaling: Trk-ing along the axon. Curr. Opin. Neurobiol. 12, 268-274.

[35] Beattie EC, Zhou J, Grimes ML, Bunnett NW, Howe CL, Mobley WC (1996) A signaling endosome hypothesis to explain NGF actions: potential implications for neurodegeneration. Cold Spring Harb. Symp. Quant. Biol. 61, 389-406.

[36] Hendry I, Thoenen H, Iversen L (1974) the retrograde axonal transport of nerve growth factor. Brain Res. 68, 103-121. 
[37] Ye H, Kuruvilla R, Zweifel L, Ginty D (2003) Evidence in support of Signaling Endosome-based retrograde survival of sympathetic neurons. Neuron 39, 57-68.

[38] Watson F, Heerssen H (1999) Rapid nuclear responses to target-derived neurotrophins require retrograde transport of ligand-receptor complex. J. Neurosci. 19, 7889-900.

[39] Bhattacharyya A, Watson FL, Pomeroy SL, Zhang YZ, Stiles CD, Segal R a. (2002) High-resolution imaging demonstrates dynein-based vesicular transport of activated trk receptors. J. Neurobiol. 51, 302312.

[40] Reid E, Kloos M, Ashley-Koch A, Hughes L, Bevan S, Svenson IK, Graham FL, Gaskell PC, Dearlove A, Pericak-Vance M a, Rubinsztein DC, Marchuk D a (2002) A kinesin heavy chain (KIF5A) mutation in hereditary spastic paraplegia (SPG10). Am. J. Hum. Genet. 71, 1189-94.

[41] Ebbing B, Mann K, Starosta A, Jaud J, Schöls L, Schüle R, Woehlke G (2008) Effect of spastic paraplegia mutations in KIF5A kinesin on transport activity. Hum. Mol. Genet. 17, 1245-52.

[42] Zhao C, Takita J, Tanaka Y, Setou M, Nakagawa T, Takeda S, Yang HW, Terada S, Nakata T, Takei Y, Saito M, Tsuji S, Hayashi Y, Hirokawa N (2001) Charcot-Marie-Tooth disease type 2A caused by mutation in a microtubule motor KIF1Bbeta. Cell 105, 587-97.

[43] Puls I, Jonnakuty C, LaMonte BH, Holzbaur ELF, Tokito M, Mann E, Floeter MK, Bidus K, Drayna D, Oh SJ, Brown RH, Ludlow CL, Fischbeck KH (2003) Mutant dynactin in motor neuron disease. Nat. Genet. 33, 455-6.

[44] Farrer M, Hulihan M, Kachergus J (2009) DCTN1 mutations in Perry syndrome. Nat. ... 41, 163-165.

[45] Baas P, Qiang L (2005) Neuronal microtubules: when the MAP is the roadblock. Trends Cell Biol. 15, 183-187.

[46] Tarrade A, Fassier C, Courageot S, Charvin D, Vitte J, Peris L, Thorel A, Mouisel E, Fonknechten N, Roblot N, Seilhean D, Diérich A, Hauw JJ, Melki J (2006) A mutation of spastin is responsible for swellings and impairment of transport in a region of axon characterized by changes in microtubule composition. Hum. Mol. Genet. 15, 3544-58.

[47] Solowska JM, Morfini G, Falnikar A, Himes BT, Brady ST, Huang D, Baas PW (2008) Quantitative and functional analyses of spastin in the nervous system: implications for hereditary spastic paraplegia. $J$. Neurosci. 28, 2147-57.

[48] Misko A, Jiang S, Wegorzewska I, Milbrandt J, Baloh RH (2010) Mitofusin 2 is necessary for transport of axonal mitochondria and interacts with the Miro/Milton complex. J. Neurosci. 30, 4232-40.

[49] Baloh RH, Schmidt RE, Pestronk A, Milbrandt J (2007) Altered axonal mitochondrial transport in the pathogenesis of Charcot-Marie-Tooth disease from mitofusin 2 mutations. J. Neurosci. 27, 422-30.

[50] Züchner S, Vance JM (2006) Mechanisms of disease: a molecular genetic update on hereditary axonal neuropathies. Nat. Clin. Pract. Neurol. 2, 45-53.

[51] Deinhardt K, Salinas S, Verastegui C, Watson R, Worth D, Hanrahan S, Bucci C, Schiavo G (2006) Rab5 and Rab7 control endocytic sorting along the axonal retrograde transport pathway. Neuron 52, 293-305.

[52] Morfini G, Pigino G, Szebenyi G, You Y, Pollema S, Brady ST (2006) JNK mediates pathogenic effects of polyglutamine-expanded androgen receptor on fast axonal transport. Nat. Neurosci. 9, 907-16.

[53] Dompierre JP, Godin JD, Charrin BC, Cordelières FP, King SJ, Humbert S, Saudou F (2007) Histone deacetylase 6 inhibition compensates for the transport deficit in Huntington's disease by increasing tubulin acetylation. J. Neurosci. 27, 3571-83.

[54] Morfini G, You Y, Pollema S (2009) Pathogenic huntingtin inhibits fast axonal transport by activating JNK3 and phosphorylating kinesin. Nat. Neurosci. 12, 864-71.

[55] Saha AR, Hill J, Utton M a, Asuni A a, Ackerley S, Grierson AJ, Miller CC, Davies AM, Buchman VL, Anderton BH, Hanger DP (2004) Parkinson's disease alpha-synuclein mutations exhibit defective axonal transport in cultured neurons. J. Cell Sci. 117, 1017-24.

[56] Bosco D a, Morfini G, Karabacak NM, Song Y, Gros-Louis F, Pasinelli P, Goolsby H, Fontaine B a, Lemay N, McKenna-Yasek D, Frosch MP, Agar JN, Julien J-P, Brady ST, Brown RH (2010) Wild-type and mutant SOD1 share an aberrant conformation and a common pathogenic pathway in ALS. Nat. Neurosci. 13, 1396-403.

[57] Pigino G, Morfini G, Atagi Y, Deshpande a, Yu C, Jungbauer L, LaDu M, Busciglio J, Brady S (2009) Disruption of fast axonal transport is a pathogenic mechanism for intraneuronal amyloid beta. Proc. Natl. Acad. Sci. U. S. A. 106, 5907-12.

[58] LaPointe NE, Morfini G, Pigino G, Gaisina IN, Kozikowski AP, Binder LI, Brady ST (2009) The amino terminus of tau inhibits kinesin-dependent axonal transport: implications for filament toxicity. $J$. Neurosci. Res. 87, 440-51.

[59] Staff NP, Benarroch EE, Klein CJ (2011) Neuronal intracellular transport and neurodegenerative disease. Neurology 76, 1015-20. 
[60] Morfini G, Burns M (2009) Axonal transport defects in neurodegenerative diseases. J. Neurosci. 29, $12776-12786$.

[61] Glenner G, Wong C (1984) Alzheimer's disease: initial report of the purification and characterization of a novel cerebrovascular amyloid protein. Biochem. Biophys. Res. Commun. 120, 885-890.

[62] Masters CL, Simms G, Weinman N a, Multhaup G, McDonald BL, Beyreuther K (1985) Amyloid plaque core protein in Alzheimer disease and Down syndrome. Proc. Natl. Acad. Sci. U. S. A. 82, 42459.

[63] Selkoe D (1998) The cell biology of $\beta$-amyloid precursor protein and presenilin in Alzheimer's disease. Trends Cell Biol. 8, 447-453.

[64] Vassar R (1999) Beta-Secretase Cleavage of Alzheimer's Amyloid Precursor Protein by the Transmembrane Aspartic Protease BACE. Science (80-. ). 286, 735-741.

[65] Wolfe MS, Xia W, Ostaszewski BL, Diehl TS, Kimberly WT, Selkoe DJ (1999) Two transmembrane aspartates in presenilin-1 required for presenilin endoproteolysis and gamma-secretase activity. Nature 398, 513-7.

[66] Binder LI, Guillozet-Bongaarts AL, Garcia-Sierra F, Berry RW (2005) Tau, tangles, and Alzheimer's disease. Biochim. Biophys. Acta 1739, 216-23.

[67] Stokin GB, Lillo C, Falzone TL, Brusch RG, Rockenstein E, Mount SL, Raman R, Davies P, Masliah E, Williams DS, Goldstein LSB (2005) Axonopathy and transport deficits early in the pathogenesis of Alzheimer's disease. Science 307, 1282-8.

[68] Salehi A, Delcroix J-D, Belichenko P V, Zhan K, Wu C, Valletta JS, Takimoto-Kimura R, Kleschevnikov AM, Sambamurti K, Chung PP, Xia W, Villar A, Campbell W a, Kulnane LS, Nixon R a, Lamb BT, Epstein CJ, Stokin GB, Goldstein LSB, Mobley WC (2006) Increased App expression in a mouse model of Down's syndrome disrupts NGF transport and causes cholinergic neuron degeneration. Neuron 51, 29-42.

[69] Pigino G, Morfini G (2003) Alzheimer's presenilin 1 mutations impair kinesin-based axonal transport. $J$. Neurosci. 23, 4499-4508.

[70] Lazarov O, Morfini G (2007) Impairments in Fast Axonal transport and motor neuron deficits in transgenic mice expressing Familial Alzheimer's Disease-linked mutant Presenilin 1. J. Neurosci. 27, 7011-7020.

[71] Tesseur I, Van Dorpe J, Spittaels K, Van den Haute C, Moechars D, Van Leuven F (2000) Expression of human apolipoprotein E4 in neurons causes hyperphosphorylation of protein tau in the brains of transgenic mice. Am. J. Pathol. 156, 951-64.

[72] Dhaenens C, Brussel E Van (2004) Association study of three polymorphisms of kinesin light-chain 1 gene with Alzheimer's disease. Neurosci. Lett. 368, 290-292.

[73] Koo EH, Sisodia SS, Archer DR, Martin LJ, Weidemann a, Beyreuther K, Fischer P, Masters CL, Price DL (1990) Precursor of amyloid protein in Alzheimer disease undergoes fast anterograde axonal transport. Proc. Natl. Acad. Sci. U. S. A. 87, 1561-5.

[74] Matsuda S, Yasukawa T, Homma Y, Ito Y, Niikura T, Hiraki T, Hirai S, Ohno S, Kita Y, Kawasumi M, Kouyama K, Yamamoto T, Kyriakis JM, Nishimoto I (2001) c-Jun N-terminal (JNK)-Interacting protein-1b/Islet-bran-1 Scaffolds Alzheimer's Amyloid Precursor Protein with JNK. J. Neurosci. 21, 6597-6607.

[75] Scheinfeld MH, Roncarati R, Vito P, Lopez P a, Abdallah M, D’Adamio L (2002) Jun NH2-terminal kinase (JNK) interacting protein 1 (JIP1) binds the cytoplasmic domain of the Alzheimer's beta-amyloid precursor protein (APP). J. Biol. Chem. 277, 3767-75.

[76] Muresan Z, Muresan V (2005) Coordinated transport of phosphorylated amyloid-beta precursor protein and c-Jun NH2-terminal kinase-interacting protein-1. J. Cell Biol. 171, 615-25.

[77] Verhey KJ, Meyer D, Deehan R, Blenis J, Schnapp BJ, Rapoport T a, Margolis B (2001) Cargo of kinesin identified as JIP scaffolding proteins and associated signaling molecules. J. Cell Biol. 152, 95970.

[78] Fu M, Holzbaur ELF (2013) JIP1 regulates the directionality of APP axonal transport by coordinating kinesin and dynein motors. J. Cell Biol. 202, 495-508.

[79] Kamal a, Almenar-Queralt a, LeBlanc JF, Roberts E a, Goldstein LS (2001) Kinesin-mediated axonal transport of a membrane compartment containing beta-secretase and presenilin-1 requires APP. Nature 414, 643-8.

[80] Sheng JG, Price DL, Koliatsos VE (2003) The B-amyloid-related proteins presenilin 1 and BACE1 are axonally transported to nerve terminals in the brain. Exp. Neurol. 184, 1053-1057.

[81] Lazarov O, Morfini G a, Lee EB, Farah MH, Szodorai A, DeBoer SR, Koliatsos VE, Kins S, Lee VM-Y, Wong PC, Price DL, Brady ST, Sisodia SS (2005) Axonal transport, amyloid precursor protein, kinesin1, and the processing apparatus: revisited. J. Neurosci. 25, 2386-95. 
[82] Prabhu Y, Burgos P V, Schindler C, Farías GG, Magadán JG, Bonifacino JS (2012) Adaptor protein 2mediated endocytosis of the $\beta$-secretase BACE1 is dispensable for amyloid precursor protein processing. Mol. Biol. Cell 23, 2339-51.

[83] Das U, Scott D a, Ganguly A, Koo EH, Tang Y, Roy S (2013) Activity-induced convergence of APP and BACE-1 in acidic microdomains via an endocytosis-dependent pathway. Neuron 79, 447-60.

[84] Mercken M, Fischer I (1995) Three Distinct Axonal Transport Rates for Tau, Tubulin and other microtubule-associated Proteins : Evidence for Dynamic Interactions of Tau with Microtubules in vivo. J. Neurosci. 15, 8259-8267.

[85] Utton M a, Connell J, Asuni A a, van Slegtenhorst M, Hutton M, de Silva R, Lees AJ, Miller CCJ, Anderton BH (2002) The slow axonal transport of the microtubule-associated protein tau and the transport rates of different isoforms and mutants in cultured neurons. J. Neurosci. 22, 6394-400.

[86] Utton M a, Noble WJ, Hill JE, Anderton BH, Hanger DP (2005) Molecular motors implicated in the axonal transport of tau and alpha-synuclein. J. Cell Sci. 118, 4645-54.

[87] Prahlad V, Yoon M, Moir RD, Vale RD, Goldman RD (1998) Rapid movements of vimentin on microtubule tracks: kinesin-dependent assembly of intermediate filament networks. J. Cell Biol. 143, 159-70.

[88] Yabe JT, Pimenta a, Shea TB (1999) Kinesin-mediated transport of neurofilament protein oligomers in growing axons. J. Cell Sci. 112 ( Pt 2, 3799-814.

[89] Prahlad V, Helfand BT, Langford GM, Vale RD, Goldman RD (2000) Fast transport of neurofilament protein along microtubules in squid axoplasm. J. Cell Sci. 113 ( Pt 2, 3939-46.

[90] He Y, Francis F, Myers K a, Yu W, Black MM, Baas PW (2005) Role of cytoplasmic dynein in the axonal transport of microtubules and neurofilaments. J. Cell Biol. 168, 697-703.

[91] Hiruma H, Katakura T, Takahashi S, Ichikawa T, Kawakami T (2003) Glutamate and amyloid betaprotein rapidly inhibit fast axonal transport in cultured rat hippocampal neurons by different mechanisms. J. Neurosci. 23, 8967-77.

[92] Rui Y, Tiwari P, Xie Z, Zheng JQ (2006) Acute impairment of mitochondrial trafficking by betaamyloid peptides in hippocampal neurons. J. Neurosci. 26, 10480-7.

[93] Decker H, Lo KY, Unger SM, Ferreira ST, Silverman M a (2010) Amyloid-beta peptide oligomers disrupt axonal transport through an NMDA receptor-dependent mechanism that is mediated by glycogen synthase kinase 3 beta in primary cultured hippocampal neurons. J. Neurosci. 30, 9166-71.

[94] Kasa P, Papp H, Kovacs I, Forgon M, Penke B, Yamaguchi H (2000) Human amyloid-b1-42 applied in vivo inhibits the fast axonal transport of proteins in the sciatic nerve of rat. Neurosci. Lett. 278, 117-119.

[95] Calkins M, Reddy P (2011) Amyloid beta impairs mitochondrial anterograde transport and degenerates synapses in Alzheimer's disease neurons. Biochim. Biophys. Acta 1812, 507-513.

[96] Wang X, Perry G, Smith M a, Zhu X (2010) Amyloid-beta-derived diffusible ligands cause impaired axonal transport of mitochondria in neurons. Neurodegener. Dis. 7, 56-9.

[97] Tang Y, Scott D a, Das U, Edland SD, Radomski K, Koo EH, Roy S (2012) Early and selective impairments in axonal transport kinetics of synaptic cargoes induced by soluble amyloid $\beta$-protein oligomers. Traffic 13, 681-93.

[98] Peineau S, Taghibiglou C, Bradley C, Wong TP, Liu L, Lu J, Lo E, Wu D, Saule E, Bouschet T, Matthews P, Isaac JTR, Bortolotto Z a, Wang YT, Collingridge GL (2007) LTP inhibits LTD in the hippocampus via regulation of GSK3beta. Neuron 53, 703-17.

[99] De Felice FG, Velasco PT, Lambert MP, Viola K, Fernandez SJ, Ferreira ST, Klein WL (2007) Abeta oligomers induce neuronal oxidative stress through an N-methyl-D-aspartate receptor-dependent mechanism that is blocked by the Alzheimer drug memantine. J. Biol. Chem. 282, 11590-601.

[100] Felice F De, Wu D, Lambert M, Fernandez SJ, Velasco PT, Lacor PN, Bigio EH, Jerecic J, Acton PJ, Shughrue PJ, Chen-Dodson E, Kinney GG, Klein WL (2008) Alzheimer's disease-type neuronal tau hyperphosphorylation induced by Ab oligomers. Neurobiol. Aging 29, 1334-1347.

[101] Leroy K, Yilmaz Z, Brion J-P (2007) Increased level of active GSK-3beta in Alzheimer's disease and accumulation in argyrophilic grains and in neurones at different stages of neurofibrillary degeneration. Neuropathol. Appl. Neurobiol. 33, 43-55.

[102] Hooper C, Killick R, Lovestone S (2008) The GSK3 hypothesis of Alzheimer's disease. J. Neurochem. 104, 1433-9.

[103] Farrimond LE, Roberts E, McShane R (2012) Memantine and cholinesterase inhibitor combination therapy for Alzheimer's disease: a systematic review. BMJ Open 2, 1-8.

[104] Yang Z, Zhou X, Zhang Q (2013) Effectiveness and safety of memantine treatment for Alzheimer's disease. J. Alzheimers. Dis. 36, 445-58.

[105] Hu S, Begum AN, Jones MR, Oh MS, Beech WK, Beech BH, Yang F, Chen P, Ubeda OJ, Kim PC, Davies P, Ma Q, Cole GM, Frautschy S a (2009) GSK3 inhibitors show benefits in an Alzheimer's 
disease (AD) model of neurodegeneration but adverse effects in control animals. Neurobiol. Dis. 33, 193-206.

[106] Del Ser T, Steinwachs KC, Gertz HJ, Andrés M V, Gómez-Carrillo B, Medina M, Vericat J a, Redondo P, Fleet D, León T (2013) Treatment of Alzheimer's disease with the GSK-3 inhibitor tideglusib: a pilot study. J. Alzheimers. Dis. 33, 205-15.

[107] Cohen P, Goedert M (2004) GSK3 inhibitors: development and therapeutic potential. Nat. Rev. Drug Discov. 3, 479-87.

[108] Peineau S, Bradley C, Taghibiglou C, Doherty A, Bortolotto Z a, Wang YT, Collingridge GL (2008) The role of GSK-3 in synaptic plasticity. Br. J. Pharmacol. 153, 428-37.

[109] Morfini G, Szebenyi G, Elluru R, Ratner N, Brady ST (2002) Glycogen synthase kinase 3 phosphorylates kinesin light chains and negatively regulates kinesin-based motility. EMBO J. 21, 28193.

[110] Morel M, Authelet M, Dedecker R, Brion JP (2010) Glycogen synthase kinase-3beta and the p25 activator of cyclin dependent kinase 5 increase pausing of mitochondria in neurons. Neuroscience 167, 1044-56.

[111] Chen S, Owens GC, Crossin KL, Edelman DB (2007) Serotonin stimulates mitochondrial transport in hippocampal neurons. Mol. Cell. Neurosci. 36, 472-83.

[112] Weaver C, Leidel C, Szpankowski L, Farley NM, Shubeita GT, Goldstein LSB (2013) Endogenous GSK-3/shaggy regulates bidirectional axonal transport of the amyloid precursor protein. Traffic 14, 295308.

[113] Chauhan A, Chauhan V, Murakami N (1993) Amyloid $\beta$-protein stimulates casein kinase I and casein kinase II activities. Brain Res. 629, 47-52.

[114] Morfini G, Pigino G (2007) Tau binding to microtubules does not directly affect microtubule-based vesicle motility. J. Neurosci. Res. 85, 2620-2630.

[115] Wagey R, Krieger C (1998) Abnormalities of protein kinases in neurodegenerative diseases. Prog. drug Res.

[116] Chung S-H (2009) Aberrant phosphorylation in the pathogenesis of Alzheimer's disease. BMB Rep. 42 , 467-474.

[117] Quintanilla R a, Muñoz FJ, Metcalfe MJ, Hitschfeld M, Olivares G, Godoy J a, Inestrosa NC (2005) Trolox and 17beta-estradiol protect against amyloid beta-peptide neurotoxicity by a mechanism that involves modulation of the Wnt signaling pathway. J. Biol. Chem. 280, 11615-25.

[118] Giese KP (2009) GSK-3: a key player in neurodegeneration and memory. IUBMB Life 61, 516-21.

[119] Calkins MJ, Manczak M, Mao P, Shirendeb U, Reddy PH (2011) Impaired mitochondrial biogenesis, defective axonal transport of mitochondria, abnormal mitochondrial dynamics and synaptic degeneration in a mouse model of Alzheimer's disease. Hum. Mol. Genet. 20, 4515-29.

[120] Tillement L, Lecanu L, Papadopoulos V (2011) Alzheimer's disease: effects of b-amyloid on mitochondria. Mitochondrion 11, 13-21.

[121] Tajes Orduña M, Pelegrí Gabalda C, Vilaplana Hortensi J, Pallàs Lliberia M, Camins Espuny A (2009) An evaluation of the neuroprotective effects of melatonin in an in vitro experimental model of ageinduced neuronal apoptosis. J. Pineal Res. 46, 262-7.

[122] Massaad C a, Amin SK, Hu L, Mei Y, Klann E, Pautler RG (2010) Mitochondrial superoxide contributes to blood flow and axonal transport deficits in the Tg2576 mouse model of Alzheimer's disease. PLoS One 5, e10561.

[123] Ye X, Tai W, Zhang D (2012) The early events of Alzheimer's disease patholgoy: from mitochondrial dysfunction to BDNF axonal transport deficits. Neurobiol. Aging 33,.

[124] Ferreirinha F, Quattrini A (2004) Axonal degeneration in paraplegin-deficient mice is associated with abnormal mitochondria and impairment of axonal transport. J. Clin. Invest. 113, 231-242.

[125] Gunawardena S, Goldstein LS (2001) Disruption of axonal transport and neuronal viability by amyloid precursor protein mutations in Drosophila. Neuron 32, 389-401.

[126] Goldsbury C, Mocanu M, Thies E (2006) Inhibition of APP Trafficking by Tau Protein Does Not Increase the Generation of Amyloid- $\beta$ Peptides. Traffic 7, 873-88.

[127] Muresan V, Muresan Z (2009) Is abnormal axonal transport a cause, a contributing factor or a consequene of the neuronal pathology in Alzheimer's disease? Future Neurol. 4, 761-773.

[128] Amos L a, Schlieper D (2005) Microtubules and maps. Adv. Protein Chem. 71, 257-98.

[129] Stamer K, Vogel R, Thies E, Mandelkow E, Mandelkow E-M (2002) Tau blocks traffic of organelles, neurofilaments, and APP vesicles in neurons and enhances oxidative stress. J. Cell Biol. 156, 1051-63.

[130] Ebneth A, Godemann R (1998) Overexpression of tau protein inhibits kinesin-dependent trafficking of vesicles, mitochondria, and endoplasmic reticulum: implications for Alzheimer's disease. J. Cell Biol. 143, 777-794. 
[131] Dixit R, Ross JL, Goldman YE, Holzbaur ELF (2008) Differential regulation of dynein and kinesin motor proteins by tau. Science 319, 1086-9.

[132] Zhang B, Maiti A, Shively S, Lakhani F, McDonald-Jones G, Bruce J, Lee EB, Xie SX, Joyce S, Li C, Toleikis PM, Lee VM-Y, Trojanowski JQ (2005) Microtubule-binding drugs offset tau sequestration by stabilizing microtubules and reversing fast axonal transport deficits in a tauopathy model. Proc. Natl. Acad. Sci. U. S. A. 102, 227-31.

[133] Cuchillo-Ibanez I, Seereeram A, Byers HL, Leung K-Y, Ward M a, Anderton BH, Hanger DP (2008) Phosphorylation of tau regulates its axonal transport by controlling its binding to kinesin. FASEB J. 22, 3186-95.

[134] Yuan A, Kumar A, Peterhoff C, Duff K, Nixon R a (2008) Axonal transport rates in vivo are unaffected by tau deletion or overexpression in mice. J. Neurosci. 28, 1682-7.

[135] Vossel KA, Zhang K, Brodbeck J, Daub AC, Sharma P, Finkbeiner S, Cui B, Mucke L (2010) Tau reduction prevents Ab-induced defects in axonal transport. Science 330, 10-13.

[136] Roberson ED, Scearce-Levie K, Palop JJ, Yan F, Cheng IH, Wu T, Gerstein H, Yu G-Q, Mucke L (2007) Reducing endogenous tau ameliorates amyloid beta-induced deficits in an Alzheimer's disease mouse model. Science 316, 750-4.

[137] Barbacid M (1994) The Trk family of neurotrophin receptors. J. Neurobiol. 25, 1386-403.

[138] Dawbarn D, Allen SJ (2003) Neurotrophins and neurodegeneration. Neuropathol. Appl. Neurobiol. 29, 211-30.

[139] Teng KK, Hempstead BL (2004) Neurotrophins and their receptors: signaling trios in complex biological systems. Cell. Mol. Life Sci. 61, 35-48.

[140] Siegel G, Chauhan N (2000) Neurotrophic factors in Alzheimer's and Parkinson's disease brain. Brain Res. Rev. 33, 199-227.

[141] Hock C, Heese K, Hulette C, Rosenberg C, Otte U (2000) Region-Specific Neurotrophin Imbalances in Alzheimer Disease. Arch Neurol 57, 2-7.

[142] Arancibia S, Silhol M, Moulière F, Meffre J, Höllinger I, Maurice T, Tapia-Arancibia L (2008) Protective effect of BDNF against beta-amyloid induced neurotoxicity in vitro and in vivo in rats. Neurobiol. Dis. 31, 316-26.

[143] Binder DK, Scharfman HE (2004) Brain-derived Neurotrophic Factor. Growth Factors 22, $123-131$.

[144] Nagahara A, Merrill D, Coppola G (2009) Neuroprotective effects of brain-derived neurotrophic factor in rodent and primate models of Alzheimer's disease. Nat. Med. 15, 331-337.

[145] Phillips H, Hains J, Armanini M (1991) BDNF mRNA is decreased in the hippocampus of individuals with Alzheimer's disease. Neuron 7, 695-702.

[146] Connor B, Young D, Yan Q, Faull RL., Synek B, Dragunow M (1997) Brain-derived neurotrophic factor is reduced in Alzheimer's disease. Mol. Brain Res. 49, 71-81.

[147] Holsinger RMD, Schnarr J, Henry P, Castelo VT, Fahnestock M (2000) Quantitation of BDNF mRNA in human parietal cortex by competitive reverse transcription-polymerase chain reaction: decreased levels in Alzheimer's disease. Mol. Brain Res. 76, 347-354.

[148] Kunugi H, Ueki A, Otsuka M, Isse K, Hirasawa H, Kato N, Nabika T, Kobayashi S (2001) A novel polymorphism of the brain-derived neurotrophic factor ( BDNF) gene associated with late-onset Alzheimer' s disease. Mol. Psychiatry 6, 83-86.

[149] Matsushita S, Arai H, Matsui T, Yuzuriha T, Urakami K, Masaki T, Higuchi S (2005) Brain-derived neurotrophic factor gene polymorphisms and Alzheimer's disease. J. Neural Transm. 112, 703-11.

[150] Huang R, Huang J, Cathcart H, Smith S, Poduslo SE (2007) Genetic variants in brain-derived neurotrophic factor associated with Alzheimer's disease. J. Med. Genet. 44, e66.

[151] Bagnoli S, Nacmias B, Tedde A, Guarnieri BM, Cellini E, Petruzzi C, Bartoli A, Ortenzi L, Sorbi S (2004) Brain-derived neurotrophic factor genetic variants are not susceptibility factors to Alzheimer's disease in Italy. Ann. Neurol. 55, 447-8.

[152] Desai P, Nebes R, DeKosky S, Kamboh M (2005) Investigation of the effect of brain-derived neurotrophic factor (BDNF) polymorphisms on the risk of late-onset Alzheimer's disease (AD) and quantitative measures of AD progression. Neurosci. Lett. 379, 229-234.

[153] Du J, Feng L, Zaitsev E, Je H (2003) Regulation of TrkB receptor tyrosine kinase and its internalization by neuronal activity and Ca2+ influx. J. Cell Biol 163, 385-395.

[154] Segal R a (2003) Selectivity in neurotrophin signaling: theme and variations. Annu. Rev. Neurosci. 26, 299-330.

[155] Heerssen H, Pazyra M, Segal R (2004) Dynein motors transport activated Trks to promote survival of target-dependent neurons. Nat. Neurosci. 7, 596-604.

[156] Poon WW, Blurton-jones M, Tu CH, Feinberg LM, Chabrier A, Harris JW, Jeon NL, Cotman CW (2012) B-amyloid impairs axonal BDNF retrograde trafficking. Neurobiol. Aging 32, 821-833. 
[157] Gardiner K, Fortna A, Bechtel L, Davisson MT (2003) Mouse models of Down syndrome: how useful can they be? Comparison of the gene content of human chromosome 21 with orthologous mouse genomic regions. Gene 318, 137-147.

[158] Chada SR (2003) Mitochondrial movement and positioning in axons: the role of growth factor signaling. J. Exp. Biol. 206, 1985-1992.

[159] Schindowski K, Belarbi K, Buée L (2008) Neurotrophic factors in Alzheimer's disease: role of axonal transport. Genes. Brain. Behav. 7 Suppl 1, 43-56.

[160] DeKosky S, Scheff S (1990) Synapse loss in frontal cortex biopsies in Alzheimer's disease: correlation with cognitive severity. Ann. Neurol. 457-464.

[161] Terry RD, Masliah E, Salmon DP, Butters N, DeTeresa R, Hill R, Hansen L a, Katzman R (1991) Physical basis of cognitive alterations in Alzheimer's disease: synapse loss is the major correlate of cognitive impairment. Ann. Neurol. 30, 572-80.

[162] Rowland KC, Irby NK, Spirou G a (2000) Specialized synapse-associated structures within the calyx of Held. J. Neurosci. 20, 9135-44.

[163] David G, Barrett EF (2000) Stimulation-evoked increases in cytosolic [Ca(2+)] in mouse motor nerve terminals are limited by mitochondrial uptake and are temperature-dependent. J. Neurosci. 20, 7290-6.

[164] Billups B, Forsythe ID (2002) Presynaptic mitochondrial calcium sequestration influences transmission at mammalian central synapses. J. Neurosci. 22, 5840-7.

[165] Zenisek D, Matthews G (2000) The role of mitochondria in presynaptic calcium handling at a ribbon synapse. Neuron 25, 229-37.

[166] Ly C V, Verstreken P (2006) Mitochondria at the synapse. Neuroscientist 12, 291-9.

[167] Stowers RS, Megeath LJ, Górska-Andrzejak J, Meinertzhagen I a, Schwarz TL (2002) Axonal transport of mitochondria to synapses depends on milton, a novel Drosophila protein. Neuron 36, 1063-77.

[168] Guo X, Macleod GT, Wellington A, Hu F, Panchumarthi S, Schoenfield M, Marin L, Charlton MP, Atwood HL, Zinsmaier KE (2005) The GTPase dMiro is required for axonal transport of mitochondria to Drosophila synapses. Neuron 47, 379-93.

[169] Chang DTW, Honick AS, Reynolds IJ (2006) Mitochondrial trafficking to synapses in cultured primary cortical neurons. J. Neurosci. 26, 7035-45.

[170] Verstreken P, Ly C V, Venken KJT, Koh T-W, Zhou Y, Bellen HJ (2005) Synaptic mitochondria are critical for mobilization of reserve pool vesicles at Drosophila neuromuscular junctions. Neuron 47, 365-78.

[171] Fejtova A, Davydova D, Bischof F, Lazarevic V, Altrock WD, Romorini S, Schöne C, Zuschratter W, Kreutz MR, Garner CC, Ziv NE, Gundelfinger ED (2009) Dynein light chain regulates axonal trafficking and synaptic levels of Bassoon. J. Cell Biol. 185, 341-55.

[172] Falzone TL, Stokin GB, Lillo C, Rodrigues EM, Westerman EL, Williams DS, Goldstein LSB (2009) Axonal stress kinase activation and tau misbehavior induced by kinesin-1 transport defects. J. Neurosci. 29, 5758-67.

[173] Hafezparast M, Klocke R, Ruhrberg C, Marquardt A, Ahmad-Annuar A, Bowen S, Lalli G, Witherden AS, Hummerich H, Nicholson S, Morgan PJ, Oozageer R, Priestley J V, Averill S, King VR, Ball S, Peters J, Toda T, Yamamoto A, Hiraoka Y, Augustin M, Korthaus D, Wattler S, Wabnitz P, Dickneite C, Lampel S, Boehme F, Peraus G, Popp A, Rudelius M, Schlegel J, Fuchs H, Hrabe de Angelis M, Schiavo G, Shima DT, Russ AP, Stumm G, Martin JE, Fisher EMC (2003) Mutations in dynein link motor neuron degeneration to defects in retrograde transport. Science 300, 808-12.

[174] Puls I, Oh S, Sumner C (2005) Distal spinal and bulbar muscular atrophy caused by dynactin mutation. Ann. Neurol. 57, 687-694.

ABBREVIATIONS: $\mathrm{AD}$, Alzheimer's disease; $\mathrm{A} \beta$, amyloid- $\beta$ peptide; $\mathrm{A} \beta \mathrm{O}$, soluble oligomers of $\mathrm{A} \beta$; $\mathrm{A} \beta \mathrm{PP}$, amyloid $\beta$ precursor protein; $\mathrm{AR}$, androgen receptor; $\mathrm{AT}$, axonal transport; BACE1, beta-site A $\beta P P$ cleaving enzyme 1; BDNF, brain-derived neurotrophic factor; CK2, casein kinase 2, CMT, Charcot-Marie-Tooth disease; CNS, central nervous system; DCTN1, dynactin complex 1; DHC, dynein heavy chain; DIC, dynein intermediate 
chain; DLC, dynein light chain; FAT, fast axonal transport; GSK3 $\beta$, glycogen synthase kinase $3 \beta$; HSP, hereditary spastic paraplegia; JIP1, JNK interacting protein 1; JNK, c-Jun NH2terminal kinase; KHC, kinesin heavy chain; KIF, kinesin superfamily; KLC, kinesin light chain; LTD, long-term depression; LTP, long-term potentiation; NFT, neurofibrillary tangles; NMDA, N-methyl-D-aspartate; NMDAR, NMDA receptor; PS1, presenilin 1; PTV, piccolobassoon transported vehicle; SBMA, spinal and bulbar muscular atrophy; SVP, synaptic vesicle precursor; Trk, tyrosin receptor kinase 
Table 1. Primary mutations of axonal transport elements

\begin{tabular}{|ccccc|}
\hline $\begin{array}{c}\text { AT } \\
\text { dysfunction }\end{array}$ & Disease & Mutated gene & Protein implicated & References \\
\hline & HSP-10 & KIF5A & Kinesin & 40,41 \\
\hline \multirow{2}{*}{ CMT2A1 } & KIF1BB & Kinesin 1 & 42 \\
\hline
\end{tabular}

Abbreviations. CMT: Charcot-Marie-Tooth disease, HSP: hereditary spastic paraplegia 10, SBMA: spinal and bulbar muscular atrophy 
Table 2. Secondary dysfunction of axonal transport

\begin{tabular}{|c|c|c|c|c|}
\hline $\begin{array}{c}\text { AT } \\
\text { dysfunction }\end{array}$ & Disease & Mutated gene & $\begin{array}{l}\text { Protein } \\
\text { implicated }\end{array}$ & References \\
\hline \multirow{7}{*}{ 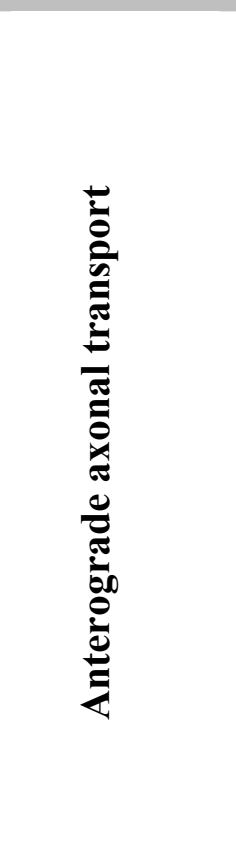 } & HSP4 & SPG4 & Spastin & $45,46,47$ \\
\hline & СMT2A2 & MFN2 & Mitofusin-2 & 48,49 \\
\hline & SBMA & AR & PolyQ AR & 52 \\
\hline & Huntington's disease & - & PolyQ huntingtin & 53,54 \\
\hline & Parkinson's disease & - & $\alpha$-synuclein & 55 \\
\hline & ALS & SOD1 & $\begin{array}{c}\text { Cu/Zn superoxide } \\
\text { dismutase-1 }\end{array}$ & 56 \\
\hline & $A D$ & - & $A \beta$, Tau & $\begin{array}{c}57,58,92- \\
94,129,130\end{array}$ \\
\hline \multirow{5}{*}{ 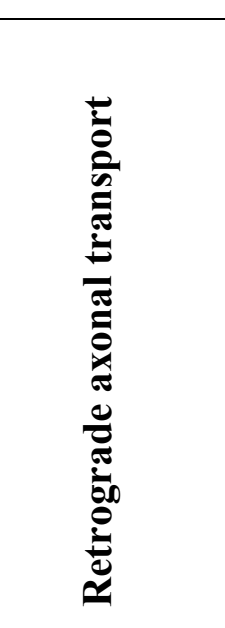 } & HSP4 & SPG4 & Spastin & $45,46,47$ \\
\hline & CMT2B & RAB7 & Rab-7 & 50,51 \\
\hline & Huntington's disease & - & PolyQ huntingtin & 51,52 \\
\hline & ALS & SOD1 & $\begin{array}{c}\mathrm{Cu} / \mathrm{Zn} \text { superoxide } \\
\text { dismutase-1 }\end{array}$ & 56 \\
\hline & $A D$ & - & $A \beta$, Tau & $\begin{array}{c}57,58,92- \\
94,129,130\end{array}$ \\
\hline
\end{tabular}

Abbreviations. ALS: amyotrophic lateral sclerosis, HSP: hereditary spastic paraplegia 10, CMT: Charcot-Marie-Tooth disease, SBMA: spinal and bulbar muscular atrophy 


\section{FIGURES LEGENDS}

Fig. 1. Anterograde axonal transport by the kinesin motor. Kinesin is composed of two kinesin heavy chain (KHC) (orange) and two kinesin light chain (KLC) (green). The KHC contains the motor domains (heads), the central coiled-coiled stalk and the tails that interact with the KLC subunits. The motor domain binds to microtubules and hydrolyzes ATP to propel cargoes along the microtubules. Cargoes are attached to the kinesin by the KLC (A). Microtubules in the axon have the plus-ends pointing towards the synaptic terminals, and provide the tracks for the kinesin. Kinesins transport mitochondria, vesicles containing A $\beta P P$, synaptic vesicle precursors (SVPs) and piccolo-bassoon transport vesicles (PTVs) towards the plus-ending of microtubules, that is, towards the nerve terminal (B).

Fig. 2. Retrograde axonal transport by the dynein motor. Dynein is a large protein complex composed of two dynein heavy chain (DHC) (orange) with the microtubule binding and ATPase domains, two dynein intermediate chain (DIC) (blue), two DLIC (yellow), several DLC subunits (Roadblock, LC8 and Tctex1) and the dynactin complex. Dynactin complex links the dynein motor to cargoes, and the largest dynactin subunit, p150Glued (purple), forms an elongated dimer that interacts with the DIC and binds to microtubules (A). Microtubules in the axon have the plus-ends pointing towards the synaptic terminals, and provide the tracks for the dynein. Dynein transports mitochondria and neurotrophins towards the minus-ends of microtubules, that is, towards the cell body (B).

Fig. 3. Signaling pathways involved in $A \beta$-dependent FAT disruption. A $\beta O$ s are suggested to interfere with NMDA-R and cause LTD-like stimuli. In LTD, calcium enters through NMDA$\mathrm{R}$ and activates PP2B, which dephosphorylates PP1 and activates it. PP1 activation leads to 
the dephosphorylation and subsequent activation of GSK3 $\beta$. GSK3 $\beta$ can then phosphorylate kinesin at the level of KLC and disrupt it from the cargoes. CK2 is also thought to phosphorylate KLC and disrupt axonal transport, but the mechanism through which A $\beta O S$ cause CK2 activation are still unknown. Similarly, it is also unknown how A $\beta$ Os produce the JNK activation that leads to phophorylation of the $\mathrm{KHC}$ and disruption from microtubule binding. 
FIGURE 1

A

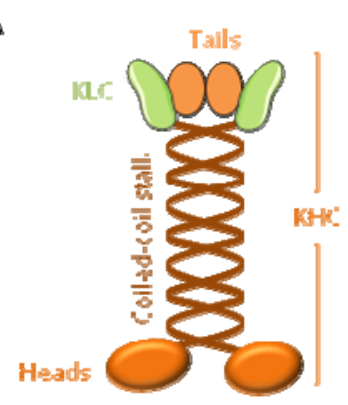

Kinesin-1
B

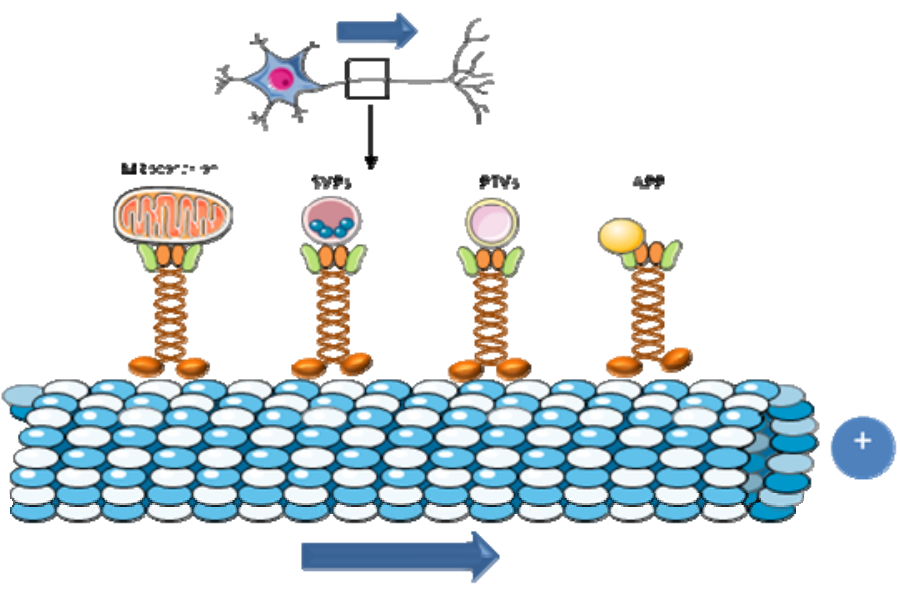

Anterograde transport 
FIGURE 2

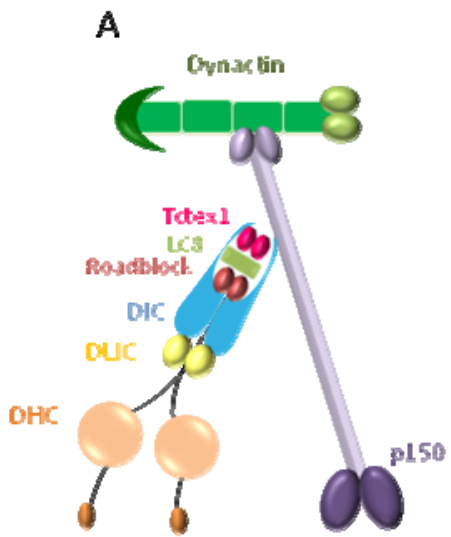

Dynein-Dynactin complex
B

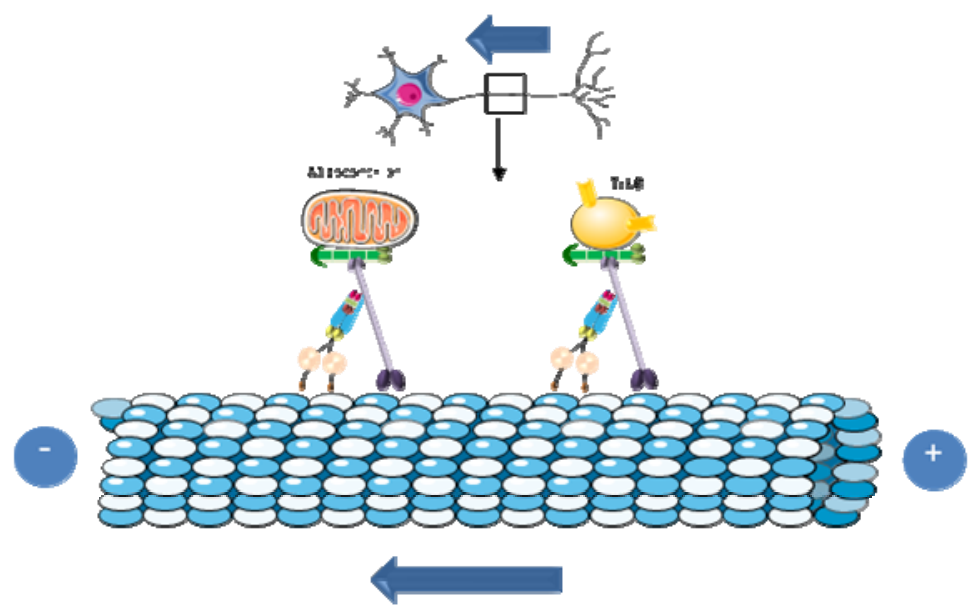

Retrograde transport 
FIGURE 3

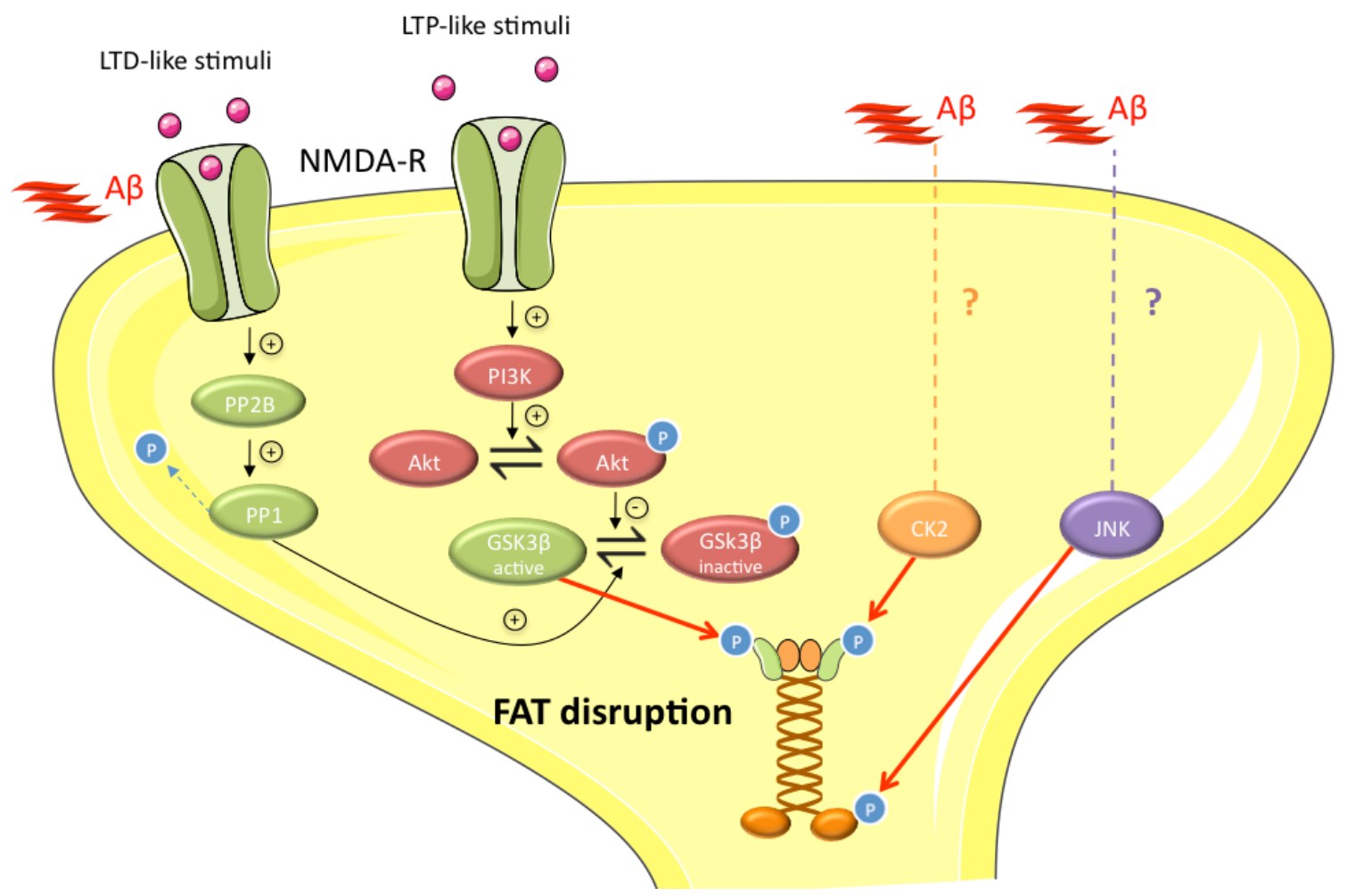

